\title{
Investigation and Analysis on the Cultivation of Academic Competence of Postgraduates
}

\author{
Yuting Zhang1, Yunlong Jiang2* \\ ${ }^{1}$ School of Business Administration, Anhui University of Finance and Economics, Bengbu, China \\ ${ }^{2}$ School of International Trade and Economics, Anhui University of Finance and Economics, Bengbu, China \\ Email: *32356576@qq.com
}

How to cite this paper: Zhang, Y.T. and Jiang, Y.L. (2021) Investigation and Analysis on the Cultivation of Academic Competence of Postgraduates. Open Access Library Journal, 8: e7967.

https://doi.org/10.4236/oalib.1107967

Received: September 14, 2021

Accepted: October 15, 2021

Published: October 18, 2021

Copyright $\odot 2021$ by author(s) and Open Access Library Inc.

This work is licensed under the Creative Commons Attribution International License (CC BY 4.0).

http://creativecommons.org/licenses/by/4.0/

\begin{abstract}
Taking 201 graduate students from some universities in Anhui and Shaanxi as the research objects, using the method of the questionnaire survey, this paper analyzes the realistic characteristics and influencing factors of the academic competence of graduate students. At the same time, the corresponding countermeasures are put forward from the individual level and the school level, and the corresponding research conclusions are expected to provide the reference for improving the academic ability of graduate students.
\end{abstract}

\section{Subject Areas \\ Higher Education}

\section{Keywords}

Academic Ability, Graduate Student, Investigation

\section{Introduction}

With the gradual transition from elite to mass higher education in China, new requirements are put forward for graduate education aiming at cultivating highquality talents. Graduate education not only meets the needs of the public but also pays more attention to the improvement of graduate quality. As the embodiment of the basic quality of academic research, postgraduate academic ability can represent the quality of postgraduate training to a large extent. Academic ability generally includes the ability to find problems, search and sort out literature, condense viewpoints, design research, and sensitivity to academic problems. In order to understand the basic situation of postgraduate academic ability 
and its main influencing factors further, this paper draws on the questionnaire design of Liu [1], 201 graduate students from some colleges and universities in Anhui and Shaanxi were investigated, analyzed the main factors affecting the cultivation of graduate students' academic ability and puts forward some specific suggestions.

\section{Investigation and Analysis on the Status Quo of Graduate Students' Academic Ability}

\subsection{Basic Information of Survey Subjects}

This research adopts the questionnaire method, issued questionnaires mainly through the questionnaire star to graduate students in 985 or 211 universities and local ordinary universities. The questionnaire mainly consists of three parts, the first part is the basic information of the respondents, including grade, cross-major, university category and number of published papers. The second part mainly investigates the academic ability of current graduate students. The third part investigates the possible factors affecting academic ability. A total of 207 questionnaires were collected, and 6 invalid questionnaires were excluded, the number of valid questionnaires was 201 with an effective recovery of $97.10 \%$.

Among them, there are 49 students from 985 or 211 universities in the sample, 152 students from local colleges and universities (Table 1). There are $121 \mathrm{stu}-$ dents in the second year of master's degree, accounting for about $60 \%$ of the total, which is the main of this investigation. After the first year of acclimation, the second-year students' feedback was more realistic, it can show the condition of early academic ability cultivation to a certain extent, it also coincides with the main objective of this study.

\subsection{Status of Academic Ability}

The second part of the questionnaire mainly focuses on the current situation of graduate students' academic ability testing. Based on Likert scale, this paper set five choices for each question, and assign values to each option according to "completely inconsistent $=1$, basically consistent $=2$, generally $=3$, basically consistent $=4$, completely consistent $=5$ ", the higher the score, the better the academic ability of the graduate students.

Table 1. Sample characteristics of the questionnaire.

\begin{tabular}{ccccc}
\hline Variable & Items & $\begin{array}{c}985 \text { or } 211 \\
\text { universities }\end{array}$ & $\begin{array}{c}\text { Local colleges } \\
\text { and universities }\end{array}$ & ratio \\
\hline first-year & 8 & 27 & $17.41 \%$ \\
Grade & second-year & 14 & 107 & $60.20 \%$ \\
third-year & one & 27 & 18 & $22.39 \%$ \\
\hline $\begin{array}{c}\text { Number of } \\
\text { published }\end{array}$ & two & 17 & 98 & $57.21 \%$ \\
\hline
\end{tabular}


It can be calculated from Table 2 that the average of the overall academic ability of graduate students is 3.48 , which equals to the mean of the sum of the dimensions and indicates that the academic ability of graduate students is just at the qualified level, there is still a lot of room for improvement. However, comparing the overall academic ability level of 985 or 211 universities and local ordinary universities, we can find that local universities generally scored lower than 985 or 211 universities, the average score was 0.34 points lower, which can be inferred in basic academic ability, local colleges and universities do show some shortcomings, there is much room for improvement.

From a single dimension of measurement, the highest overall score was for logical thinking, it can be considered that the overall logical thinking ability of the respondents is basically up to standard, the overall quality of the current students has been improved. The overall score of integrated innovation ability is the lowest, only $8.5 \%$ of the students think they have the ability of interdisciplinary integration and innovation, there are 123 people who think their integrated innovation ability is not up to standard, the proportion reached $61.5 \%$, still a lot of room for improvement. This is also the current postgraduate training pain point, how to improve the independent learning and innovation ability of graduate students will be the key problem to be solved for a long time in the future, the core of postgraduate academic ability. The score of the practice generalization ability of postgraduates is also low, about $58.5 \%$ of the respondents believed that their ability to apply relevant conclusions of scientific research into practice still needs to be improved. In fact, in the course of academic research, there is often a disconnect between theory and practice, it affects the explanatory power and universality of the theory, also affects the application of practice, it should be taken into consideration in the future cultivation process. The sensitivity of graduate students to scientific research problems needs to be improved. To some extent, sensitivity to scientific research issues plays an important role in the cultivation of graduate students' academic ability. Although you can do this by constantly reading the literature, summarize scientific research topics to gradually improve the sensitivity of scientific research issues but there is another case inevitably, that is, they have an aptitude for research, the findings suggest that this is indeed the case.

Table 2. Research status of postgraduate academic ability.

\begin{tabular}{ccccc}
\hline Dimension of academic ability & $\begin{array}{c}985 \text { or } 211 \\
\text { universities }\end{array}$ & $\begin{array}{c}\text { Local colleges } \\
\text { and universities }\end{array}$ & $\begin{array}{c}\text { Total } \\
\text { score }\end{array}$ & Rank \\
\hline Logical thinking ability & 3.86 & 3.50 & 3.68 & 1 \\
Language organization ability & 3.85 & 3.41 & 3.63 & 2 \\
Integrated innovation capability & 3.42 & 3.06 & 3.24 & 6 \\
Academic sensitivity & 3.54 & 3.32 & 3.43 & 4 \\
Knowledge application ability & 3.72 & 3.36 & 3.54 & 3 \\
Practical generalization ability & 3.50 & 3.22 & 3.36 & 5
\end{tabular}




\section{An Analysis of the Influencing Factors of Postgraduate Academic Ability}

The cultivation and development of academic ability are often influenced by internal and external factors, this paper draws on the analytical ideas of existing studies, the internal factors are divided into three aspects: knowledge structure, cognitive interest and self-management, external factors can be considered from school support, scientific research atmosphere and the role of tutors, specific analysis in Table 3.

It can be seen from Table 3, among the internal factors, first, cognitive interest has the greatest impact on academic ability. According to the questionnaire, $87.5 \%$ of the students think they want to study for academic research, pursue the enjoyment of knowledge and satisfy cognitive interest. This intrinsic factor is the strongest driving force and therefore has the greatest impact on academic ability. The difference of the influence effect between 985 or 211 universities and local universities is the smallest, which indicates the influence of cognitive interest on graduate students' academic ability has a certain commonality to some extent. Second, the influence of self-management on graduate students' academic ability ranks second. Whether the graduate students are willing to take the initiative to participate in various academic activities of the university or the professional organization, and then dig out the subjective initiative of graduate students' independent learning, constantly absorb new knowledge and cutting-edge problems, it has a great influence on the construction and cultivation of graduate students' academic ability. At the same time, whether graduate students can make learning plans and strictly implement them according to the learning requirements and their own reality, whether they can take the initiative to write reading notes and think positively in the learning process reflects the self-discipline of graduate students to a certain extent and has a fundamental impact on academic ability. It can be said that the cultivation of academic ability is influenced by

Table 3. Analysis on the influencing factors of postgraduate academic ability.

\begin{tabular}{cccccc}
\hline Factor categories & Dimension & $\begin{array}{c}985 \text { or } 211 \\
\text { universities }\end{array}$ & $\begin{array}{c}\text { Local colleges } \\
\text { and universities }\end{array}$ & $\begin{array}{c}\text { Total } \\
\text { score }\end{array}$ & Rank \\
\hline Internal factors & Self-management & 3.53 & 3.48 & 3.50 & 1 \\
& Knowledge structure & 3.52 & 3.39 & 3.46 & 2 \\
\hline $\begin{array}{c}\text { External factors: } \\
\text { scientific research } \\
\text { atmosphere }\end{array}$ & Academic culture & 3.94 & 3.30 & 3.41 & 3 \\
\hline $\begin{array}{c}\text { External factors: } \\
\text { mentor role }\end{array}$ & Research fund & 3.71 & 4.13 & 3.92 & 3 \\
\hline $\begin{array}{c}\text { External factors: } \\
\text { School support }\end{array}$ & Mentor role & 4.00 & 3.86 & 3.93 & 2 \\
\hline Anfrastructure & 3.85 & 3.81 & 3.83 & 5 \\
\hline
\end{tabular}


many factors, however, the individual learning attitude and self-discipline of graduate students are the foundation and cannot be ignored. Thirdly, the influence of knowledge structure on graduate students' academic ability is quite different between the two types of universities. It can be argued that of all the internal influences, the influence of knowledge structure has the greatest difference, which indicates that the cultivation of graduate students' academic ability has a certain relationship with the knowledge accumulation in the early stage.

Among the external influencing factors, firstly, scientific research atmosphere has the greatest influence on the academic ability of graduate students. The results of the survey show that the impact of research atmosphere on graduate students' academic ability is almost 4 points. About $74 \%$ of the students work in schools that provide support or encouragement for students to carry out various academic research activities, $24.5 \%$ of the students thought that the support level of the school policy was general and just reached the basic standard. Nearly $98.5 \%$ of the students' schools or majors regularly organize and provide opportunities for academic exchanges, and $77 \%$ of the students think that the academic atmosphere in their schools or majors is good for students to carry out scientific research. Secondly, the influence of tutor's role on graduate student's academic ability is second. Surveys show that 90 percent of tutors hold regular academic seminars to encourage students to continue to accumulate and improve. $70 \%$ of tutors ask students to write reading notes, and $93 \%$ guide students to participate in project research. Nearly $98 \%$ of the respondents strongly agree with the importance of regular guidance and supervision by tutors for the cultivation of academic ability. Under the guidance and guidance of tutors, students can grasp the cutting-edge knowledge and research context in the discipline more quickly, which is very important for the cultivation of postgraduate academic ability. Thirdly, the support of the school should not be ignored. The school has a certain influence on the cultivation of graduate students' academic ability in the setting of courses and learning places. Among them, 66.5 percent of the students' schools have provided special places for self-study and academic research for their classmates' research activities, but more than 30 percent have not. $99 \%$ of colleges and universities offer rich professional courses and courses with pioneering achievements for postgraduates, but there are some shortcomings in international and practical courses.

On the whole, the scores of 985 or 211 universities and local ordinary universities in the test of influencing factors of postgraduate academic ability are the same. The main factors involved in the survey are some common and more general elements, which can better reflect the universality of the analysis of influencing factors.

\section{Countermeasures to Improve the Academic Ability of Graduate Students}

The cultivation of graduate students' academic ability is a gradual process, which is the result of the comprehensive influence of internal and external factors. 
Combined with the above analysis results, this paper puts forward corresponding countermeasures from individual level and school level respectively, which can be used for reference by the majority of graduate students and their training institutions.

\subsection{The Individual Level}

According to the results of the survey, the knowledge structure, cognitive interest and self-management of graduate students are the three main internal factors that affect the cultivation of their academic ability. Knowledge structure can be optimized and perfected by constantly learning new knowledge and mastering new methods in the process of influence. Cognitive interest can be improved by actively participating in various academic activities and expanding the scope of literature reading, while self-management often depends on the self-discipline of graduate students.

\subsubsection{Encourage Students to Actively Participate in Academic Activities at All Levels}

For scientific research activities, academic innovation is the most important and core element and ability [2]. The academic innovation ability of graduate students is based on the accumulation of existing knowledge, through the cultivation of various thinking abilities, research content and research methods and other aspects of marginal innovation and breakthrough. According to the findings, graduate students have the lowest score of integrated innovation ability, although there are many factors, encouraging students to take an active part in all kinds of academic activities may be one of the effective ways to acquire new perspectives and ideas. By participating in multidisciplinary, especially interdisciplinary academic exchanges, is helpful for students to keep up with the frontier of relevant research fields and grasp the latest trends of subject fields in time [3]. At the same time, academic exchanges facilitate communication between peers, graduate students are likely to have a lot of collision of ideas in the process of participation, so as to inspire students' scientific research inspiration, which is very important for carrying out scientific research and cultivating graduate students' academic ability.

\subsubsection{Attach Importance to the Cultivation of Academic Interests}

While the academic path can be bumpy, you can make it more interesting by gradually developing your interests. The cultivation of academic interest can be advanced step by step. For example, in the early years of school, advisors should get to know the individual characteristics of students as soon as possible, some students have strong logical thinking ability, others have strong writing skills, some students work hard but find it difficult to grasp learning methods. Facing different students, instructors can combine their own research direction and students' expertise to develop targeted training plans to protect students' interest in learning [4]. Consider starting by reading the literature, assign learning tasks around a topic regularly to stimulate students' learning initiative. Let the stu- 
dents find their own information, solve the problem, and then develop students' interest in learning. With the gradual establishment and improvement of research interest, the difficulty of the problem can be further increased to satisfy the sense of accomplishment after solving the problem. Of course, participating in various academic discussions and academic practice activities also contributes to the cultivation of interest in learning [5]. For example, by encouraging students to actively apply for research projects, instructors are responsible for guidance and supervision, which is not only conducive to stimulating students' analytical and innovative abilities, it also helps to promote students' interest in scientific research and achieve a certain degree of win-win.

\subsubsection{Keep Reading and Combing the Literature}

Graduate study is different from undergraduate study in that students not only have to concentrate on the classics of their major in the early stage, but more attention should be paid to the classical literature in this field, especially those from the top journals. Read the literature every day, write reading notes, and comb the literature regularly, which not only helps students to quickly understand the research status of this field and grasp the main research context, it is also helpful for students to be familiar with relevant research methods and clear possible research entry points. In a word, reading literature is the most basic and effective way to cultivate students' academic ability, as well as one of the most effective ways to improve students' self-management ability. Qualitative change requires a lot of accumulation, without a large number of literature reading stages, it is difficult to carry out the writing of the paper. Therefore, it is very important to persist in reading and sorting out literature to improve the academic ability of postgraduates.

\subsection{School Level}

\subsubsection{Create an Academic Atmosphere}

A good scientific research atmosphere has a subtle influence on the cultivation of graduate students' academic ability. A good academic atmosphere often needs the organic cooperation of the school system, learning environment and behavior subjects, as follows: First, the academic management system and evaluation system of colleges and universities help to create a standardized academic atmosphere. The university can carry out learning activities on academic ethics, academic incentives, academic evaluations and other related systems at the early stage of graduate enrollment. Strictly regulating students' academic behavior from the initial stage is beneficial to the orderly development of the overall research activities of graduate students. Second, colleges and universities create a good academic environment. For example, the library can be equipped with several seminar rooms, and several independent corners next to the self-study room for temporary discussion of graduate students, and so on. The third is to normalize the reporting and discussion mechanism of the research group. Research group members or peers should organize regular research progress reports and discussions, feedback the research progress and experience of a period of time, 
which can not only urge graduate students to study regularly, but also stimulate the innovative thinking of the research team, so as to achieve the goal of common progress.

\subsubsection{Optimize Course Structure}

The setting of curriculum system in postgraduate training stage will have an important influence on the knowledge structure, academic ability and academic sensitivity of postgraduate. In view of the current single curriculum, international vision and practicality need to be enhanced and other reasons, which can be further improved by diversifying the curriculum system and emphasizing the practicality of the curriculum. First, it is important to build a diversified curriculum system. In the teaching process of graduate students, more courses reflecting the interdisciplinary nature should be encouraged. It not only helps to keep up with the most cutting-edge research progress and research results, but also helps to inspire the open thinking of graduate students and improve their academic ability. Second, focus on the introduction of cutting-edge or international courses. In the curriculum setting of graduate students, thematic courses such as relevant classical works or classical literature reading and introduction of cutting-edge methods can be considered, flexible and effective, conducive to the development of postgraduate interest in learning and academic ability. Third, to emphasize the practicality of the course, it is necessary to coordinate the distribution of practical courses, lecturers need to link practical lessons to research projects, use special lectures to encourage graduate students to actively participate in corresponding research projects, apply theory to practice and comprehend the true meaning of theory in practice.

\subsubsection{Establish a Scientific and Effective Guidance Mechanism for Tutors} Tutor's teaching by words and deeds runs through the whole training process of graduate students, which is very important to the training of graduate students' academic ability. Therefore, schools can consider the following three aspects to build a scientific and effective mentor guidance mechanism, so that it can play a positive role. First, strictly select tutors. Colleges and universities need to formulate scientific and strict systems in the evaluation of instructors' qualifications, scientific research tasks, financial support and employment assessment, etc. Carry out the dynamic audit of the instructor, and truly select the high-level and high-quality instructor, it is beneficial to the cultivation and development of graduate students' academic ability. Second, set up a mentor group. It is suggested to set up a mutually beneficial mentor group among relatively focused peers, graduate students in the supervisor group can regularly carry out academic research activities, investigation and practice, academic salon, etc [6]. It can not only avoid the deficiency of single tutor in the process of postgraduate training, but also through the collision of ideas between team members, get more valuable ideas and perspectives, it is beneficial to further expand the research field, deepen the research content and promote the rapid growth of graduate students. Third, pay attention to the guidance process assessment. Streng- 
then the process supervision and assessment of tutors, specific and detailed guidance objectives and implementation plans should be formulated at the beginning of each semester, the supervisor should pay attention to the reasonable arrangement of time and task requirements for the training of postgraduates. For example, it can be recommended that graduate students have at least six hours of effective study a day, five days a week, other time can be flexibly arranged according to the actual progress of the research task. Instruct teachers to check the research progress according to the task plan, urge graduate students to share research results and timely improve the research plan. The mid-term assessment and research achievements of graduate students are related to the assessment of their supervisors.

\section{Conclusions and Discussions}

Taking 201 graduate students from some universities in Anhui and Shaanxi as research objects, this paper analyzes the realistic characteristics and influencing factors of graduate students' academic ability by means of the questionnaire survey. Through the above analysis, the following conclusions can be drawn:

First, students should actively participate in all kinds of academic activities at all levels and constantly cultivate their academic interests. And in daily learning, we should pay attention to literature reading and sorting, improve the ability to find problems, extract problems and solve problems. Second, schools should create an all-round academic atmosphere, establish a scientific and effective tutor guidance mechanism, and realize the organic cooperation in the school system, learning environment and behavior subjects. At the same time, attention should also be paid to optimizing the structure of postgraduate courses, highlighting the practicality and diversification of courses.

Of course, although this paper tries to analyze the cultivation of graduate students' academic ability based on the results of the questionnaire survey, there are still several limitations to be improved in the future. For example, the research object can be expanded beyond Anhui and Shaanxi. The analysis of influencing factors can be further refined to analyze the possible elements.

\section{Funding}

This thesis is supported by Anhui University of Finance and Economics graduate Education Innovation project (No. cxjhjyyb2004) and Teaching research project of Anhui University of Finance and Economics (No. acjyyb2019015).

\section{Conflicts of Interest}

The authors declare no conflicts of interest.

\section{References}

[1] Liu, X.X. (2019) A Study on the Academic Ability Development of Postgraduate Students in Education. Master Thesis, Henan Normal University, Xinxiang. 
[2] Zhao, W. (2021) Exploration and Practice of Innovation Ability Training Mechanism for Academic Postgraduates. Comparative Study of Cultural Innovation, 5, 11-13.

[3] Liu, E.Z., Chen, L.Y. and Dan, Y. (2021) Cultivation and Thinking of Graduate Students' Academic Communication Ability-A Case Study of School of Chemical Engineering, Northwest University. Education and Teaching Forum, 13, 173-176.

[4] Jiang, L.B., Zhu, W.X. and Fu, C.R. (2021) Research on the Factor Structure and Development Mechanism of Academic Literacy of Academic Postgraduates. Heilongjiang Higher Education Research, 39, 98-102.

[5] Qiu, M.H. (2021) Practical Ability Training of Academic Postgraduates in Application-Oriented Universities: Orientation, Structure and Path. Higher Education Forum, 37, 90-93+96

[6] Luo, J.G., Xie, Z.W. and Mo, L.R. (2021) Mentoring Interaction Patterns and the Development of Graduate Students' Academic Competence: A Qualitative Analysis Based on Grounded Theory. Academic Degrees \& Graduate Education, 38, 15-20. 


\section{Appendix}

"Investigation and Analysis on the Cultivation of Academic Competence of Postgraduates."

Explanation of the Revision

Question 1. In order to understand the basic situation of postgraduate academic ability and its main influencing factors further, this paper draws on the questionnaire design of Liu [1], 201 graduate students from some colleges and universities in Anhui and Shaanxi were investigated. Is 201 a reasonable sample size? Please explain the rationality of sample size.

Response 1: In our questionnaire, three grades of graduate students are included, the sample can explain the topic clearly. And in the paper of Liu [1], there were only about 200 samples. So, we took that as a reference.

Question 2. Table 1 is the sample characteristics of the questionnaire, there are only the number of questionnaires in the table, but there is no number of valid questionnaires. Please supplement the valid questionnaires.

Response 2: The content has been added as " $A$ total of 207 questionnaires were collected, and 6 invalid questionnaires were excluded, the number of valid questionnaires was 201 with effective recovery of $97.10 \% . "$

Question 3. It is said that it can be calculated from Table 2 that the average of the overall academic ability of graduate students is 3.48 , it indicates that the academic ability of graduate students is just at the qualified level, and there is still a lot of room for improvement. It can't get the data of 3.48 directly from table, please have an explanation.

Response 3: The content has been added as "It can be calculated from Table 2 that the average of the overall academic ability of graduate students is 3.48 , which equals to the mean of the sum of the dimensions."

Question 4. It can be seen from Table 3, among the internal factors, First, cognitive interest has the greatest impact on academic ability, $87.5 \%$ of the students think they want to study for academic research, pursue the enjoyment of knowledge and satisfy cognitive interest. Table 3 is the analysis on the influencing factors of postgraduate academic ability, in the table, there only has score and rank, doesn't has any data of percentage.

Response 4: Sorry, we left out a sentence, and we supple them now. As "First, cognitive interest has the greatest impact on academic ability. According the questionnaire, $87.5 \%$ of the students think they want to study for academic research, pursue the enjoyment of knowledge and satisfy cognitive interest."

Question 5. The paper lacks of final conclusion, which is the most important content in the research. Please add a final conclusion to the research to summarize the whole paper and make the structure complete.

Response 5: The content has been added as "Taking 201 graduate students from some universities in Anhui and Shaanxi as research objects, this paper analyzes the realistic characteristics and influencing factors of graduate students academic ability by means of questionnaire survey. Through the above analysis, 
the following conclusions can be drawn:

First, students should actively participate in all kinds of academic activities at all levels and constantly cultivate their academic interests. And in daily learning, we should pay attention to literature reading and sorting, improve the ability to find problems, extract problems and solve problems. Second, schools should create an all-round academic atmosphere, establish a scientific and effective tutor guidance mechanism, and realize the organic cooperation in school system, learning environment and behavior subjects. At the same time, attention should also be paid to optimizing the structure of postgraduate courses, highlighting the practicality and diversification of courses."

Question 6. In order to better study the topic in the future, please discuss the deficiency of the article in the conclusion.

Response 6: The content has been added as "Of course, although this paper tries to analyze the cultivation of graduate students academic ability based on the results of questionnaire survey, there are still several limitations to be improved in the future. For example, the research object can be expanded beyond Anhui and Shaanxi. The analysis of influencing factors can be further refined to analyze the possible elements." 